\title{
55. Jahrestagung der Deutschen Gesellschaft für Neuroradiologie e.V. neuroRAD 2020
}

\section{7.-09.10.2020 Frankfurt am Main}

Neue Arbeitswelten - wie und woran arbeiten wir in Zukunft?

Liebe Kolleginnen und Kollegen,

im Namen des gesamten Vorstands der DGNR und meines Teams in Dresden darf ich Sie herzlich zur 55. Jahrestagung der Deutschen Gesellschaft für Neuroradiologie e. V. im Oktober 2020 nach Frankfurt/ Main einladen.
Als Motto des neuroRAD 2020 haben wir den Titel Neue Arbeitswelten gewählt. Er transportiert etwas von dem enormen gesellschaftlichen Wandel, in dem wir als Ärztinnen und Ärzte wirken: Wie gehen wir für unser Fach Neuroradiologie damit um? Welche innovativen Arbeitsmodelle gibt es, um den Herausforderungen zu begegnen und die Chancen des technischen Wandels optimal zu nutzen?

Unser Motto hat darüber hinaus einen zweiten, dezidiert medizinischen Aspekt: Durch neue Therapien - Stichwort Antikörpertherapien - werden wir mit neuen Krankheitsbildern und -verläufen konfrontiert, bei deren Aufklärung und Monitoring unser Fach eine zentrale Rolle spielt.

Allen hier angeschnittenen Themen werden wir uns gemeinsam mit ausgewiesenen Experten widmen.

Weitere Themenschwerpunkte auf dem neuroRAD 2020 sind: 


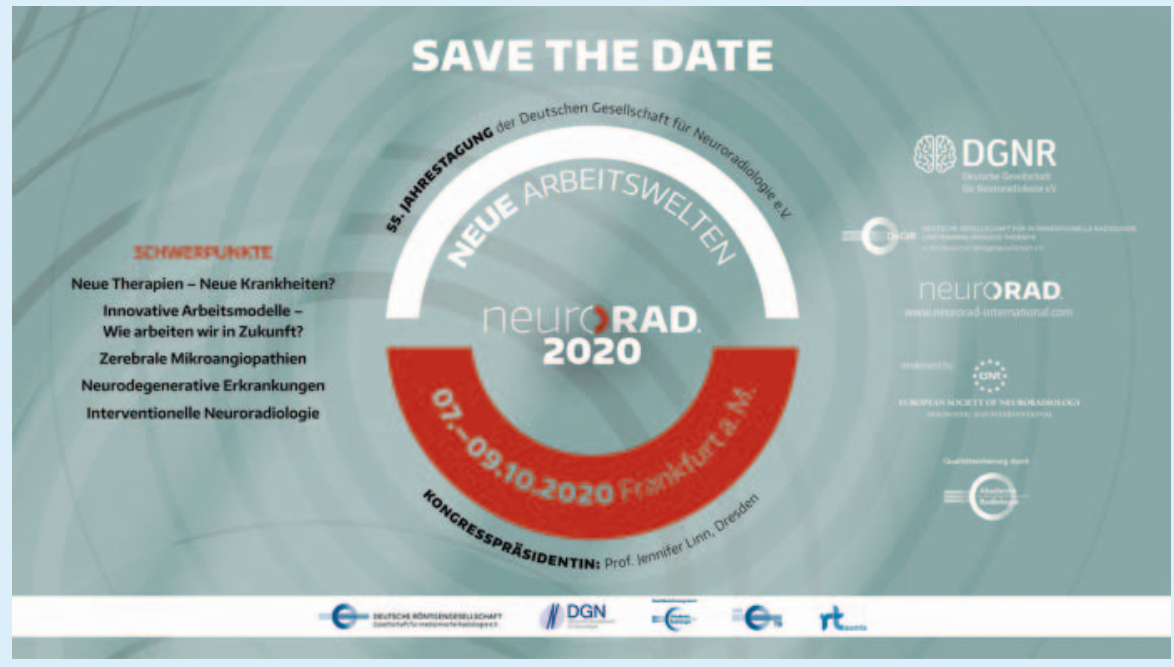

- Zerebrale Mikroangiopathien

- Neurodegenerative Erkrankungen

- Neuroonkologie

- Interventionelle Neuroradiologie

Darüber hinaus werden wir erfolgreiche Kongressformate fortsetzen: die German Stroke School, die StAR-Lounge, das Forum für medizinische Start-Ups und Anwender, die Power Pitches und die Inter-
Und selbstverständlich bieten wir auch den MTRA und den MTRA-Schülerinnen und -Schülern einen spannenden und innovativen Kongress. Die Programmvorbereitung liegt in bewährten Händen der Vereinigung Medizinisch-Technischer Berufe (VMTB) in der DRG.

Hinsichtlich der Kongressgestaltung gibt es eine wichtige Neuerung: Auf vielfachen Wunsch der Kongressteilnehmer starten wir 2020 bereits mit dem Mittwoch als vollen Kongresstag. Bitte halten Sie sich auch den Mittwochabend schon heute frei, denn wir werden den ersten Kongresstag mit einem gemeinsamen Festabend ausklingen lassen.

Schon heute freue ich mich auf den wissenschaftlichen und kollegialen Austausch!

Mit herzlichen Grüßen

Prof. Dr. med. Jennifer Linn Kongresspräsidentin 55. Jahrestagung der DGNR 07.-09.10.2020 